\title{
An Empirical Study on Multimodal Videotext Learning Strategy to English Audio- visual-oral Ability Improvement
}

\author{
Author: YAO Fanmei (Associate Professor) \\ Foreign Languages School, Wuhan Textile University \\ Wuhan, China \\ E-mail:yfm915@126.com
}

\begin{abstract}
In today's high-speed development in digital and information, human communication activities appear the phenomenon of the integration of various symbols, the phenomenon of multimodal discourse is one of the important characteristics of the use of various texts in human communication today. While the traditional single-mode teaching of audio-visual course cannot effectively improve students' audio-visual-oral skills, this paper studies on videotext learning strategies based on multimodal theory, discusses how to use task-oriented cooperative learning strategy to improve students' audio-visual-oral ability, solve the problem of language learning by the mechanization separated real context output. Conclusion: multimodal videotext teaching mode plays a considerable role to cultivate students' autonomous learning ability, improve the students' master consciousness, the language comprehensive ability, and cultural literacy. It plays a positive role in guiding the practice in the new reform of English teaching.
\end{abstract}

Key words- Multimode; videotext learning strategy; English audio-visual-oral

\section{INTRODUCTION}

Human civilization originated from the era of reading. The person's cognition also derived from the image symbol or verbal sign. Research shows that about $85 \%$ of people are born with preference for visual learners. Along with the continuous development of network technology, a large number of free online video websites such as You Tube, Tudou, Youku, QIY, Sohu, MOOCs provide a large number of free video resources, which provide vivid corpora for language learners. These containing text, images, sound, and other visual effects (Eve, 2009:156) [1] belong to the typical multimodal video discourse that play an irreplaceable role in people's life.

Films and speech video as corpus being very popular to the contemporary college students are becoming the mainstream of cultural form in university campus. It is the burning event how to guide the students effectively to become modern network beneficiaries rather than the victim. But the traditional single-mode teaching which separates audio-visual-oral training cannot effectively improve the students' pragmatic competence. Considering teaching is not only to pay attention to teachers how to teach, but more to students how to learn. Combining with the instruction of the National Medium-and Long-Term Plan for Education Reform and Development (2010-2020), according to the
Course Requirements, we decide to start with analysis of multimodal video language learning strategies. Most of the researches are the theoretical analysis of static corpus for language and it is not enough using multidisciplinary theory to research video language learning strategy. It is rather lack of concrete application to audio-visual teaching. This topic through empirical research explores a set of practical, informative and interesting audio-visual teaching methods.

\section{LITERATURE REVIEW}

\section{A. Overseas Research}

In the early 21st century multimodal theory develops rapidly, which is based on Michael O 'Toole's "The Language of Displayed Art”, which functional linguistics theory is applied to analysis of art, Kress G \& van Leeuwen's (1996) "Reading Images: The Grammar of Visual Design"[2], which is established visual grammar image analysis framework theory. The representative Cope and Kalantzis (2000) [3] explore the text teaching in the process of globalization now and the future; Kress $G$ \& van Leeuwen T (2001) study multimodal classroom teaching. On multimodal research methods, Baldry and Thibault's (2006) [4] "Multimodal Transcription and Text Analysis", makes up for the multimodal discourse analysis in the field blank. in which the multimodal discourse is introduced the transcription and analysis method in detail, such as teaching materials, web pages, movies, cartoons, etc. Meanwhile, the book also introduces how to use multimodal discourse analysis approach to promote the teaching in network learning environment. The study on multimodal discourse analysis is in full swing in foreign countries.

\section{B. Domestic Research}

Domestic multimodal discourse analysis research has just started in recent years, but also made a lot of progress. Theoretical exploration results have basically: Li Zhanzi (2003) by using the theory of system functional language to research multimodal discourse; Professor Zhu yong-sheng (2007) on the introduction of foundational theory of multimodal discourse analysis and research method, discoursing analysis should not be confined to the language itself, should pay attention to the image, sound, color and other meaning forms; Hu Zhuanglin (2007)[5] discussing the difference between multimodal semiotics and multimedia semiotics; Zhang Delu (2009) exploring the theoretical framework of multimodal discourse analysis. 
Scholars apply the theory of multimodal discourse analysis to analyze different corpora. But the research in multimodal videotext learning strategy at home and abroad is very lack, so it is necessary for the research which is full of great forward-looking significance.

\section{Theoretical basis}

This research has its theoretical basis of multimodal discourse analysis, combines task-based cooperative learning strategy which is the latest development results of western language teaching and also the latest development of the communicative approach laying stress on learning by doing. "The purpose of language teaching in the design and use of the task is to develop students' language skills, so the task is to express the significance of activities for the purpose of language use” (Eillis.2003:3) [6]. Willis (1996) [7] identified six main types of tasks, including listing, ordering and sorting, comparing, solving problem, sharing personal experiences and creative task. He claims that the task-based language teaching model meets the four basic conditions: a wealth of real language contact; the real opportunity to use language; encouragement of the learning motivation; the focus of language forms. From the perspective of language learning, Breen (1987) claimed that a task is a basic unit for designing language classroom activity. It has basic features which are specific purpose, proper content, stipulated process and a series of results. In the $80^{\prime} \mathrm{s}$ and $90^{\prime} \mathrm{s}$ of the 20th century through a large number of practical test, cooperative learning approach is widely accepted as an effective teaching mode which places the students as the center, from "practice" to study, is thought the knowledge acquired not primarily by teachers to teach students, but by learners in certain situations (i.e., social and cultural background), with the help of others (including teachers and learning partners), using the necessary learning materials by way of meaning construction. Task-based cooperative learning strategy is in the process of task performance, which gives full play to the learners themselves' cognitive ability to participate in, experience, interact, communicate and cooperate in study , arouse their existing resources in the target language, perception, understanding and application in the target language. All of the methods are heavily rooted in linguistic theories, theories of learning or theoretical assumptions on the nature of linguistic communication.

\section{RESEARCH DESIGN}

\section{A. Research Aim}

This study is based on English audio-visual-oral course in our university as the main body, through the comparative analysis of teaching mode and the effect of multimodal video discourse and traditional mode, discusses the application of cooperative learning strategy in English audio-visual course, puts forward that to take cooperative learning strategy under the " task "construction to encourage and organize students in class is to improve students' audiovisual skills and language communicative ability, cultivate the spirit of cooperation, the effective method to realize the coordinated development of individuals and groups, seek a kind of most effective audio-visual-oral teaching mode. Its teaching effect is mainly measured by the impact on the students' language output level. This paper intends to solve the problems of the key points mentioned below.

1) What is the specific influence in the cultivation of comprehensive quality by investigating the multimodal video discourse connotation of learning strategy, through the application of task-oriented cooperative learning strategies, to improve the student's ability of English audiovisual-oral?

2) What task-based cooperative pattern and evaluation mechanism of teachers and students can get more recognition to achieve the best learning effect according to the characteristics of the multimodal video language learning?

3) Which level of students for the team in cooperative learning strategy is more effective, "advantage", or "vulnerable groups"?

\section{B. Research method}

By questionnaire survey, asking individual, classroom observation and result analysis, teachers understand the language training effect of learners to fulfill, and cooperation in the process of learning methods, strategies, cultural knowledge and emotional acquirement, so on and so forth, test and demonstrate the feasibility and significance of task-based cooperative learning strategy in video discourse teaching mode, attempt to put forward effective way in line with the English audio-visual-oral learning mode.

\section{Research steps}

This research obtains evidence through investigation. Respondents for non-English major with random sample of Wuhan Textile University undergraduate class A and class B, 120 students, 59 as the control group in class A, 61 as the experimental group in class $\mathrm{B}$.

Experimental basic procedure is as follows:

\section{1) Pre-test}

Taking the output level test before teaching for the control group and experimental group, in January 2012 a freshman's final exam for listening and speaking test which is a unified exam, accounts for $20 \%$ of the final score, table 1 shows results no significant differences between the two classes before the experiment exam, especially in listening aspect, so there is a reason to believe that the result of different experiment is caused by different teaching modes. 
Table 1 Pretest Data Analysis of Two Groups in the First Term Fig1

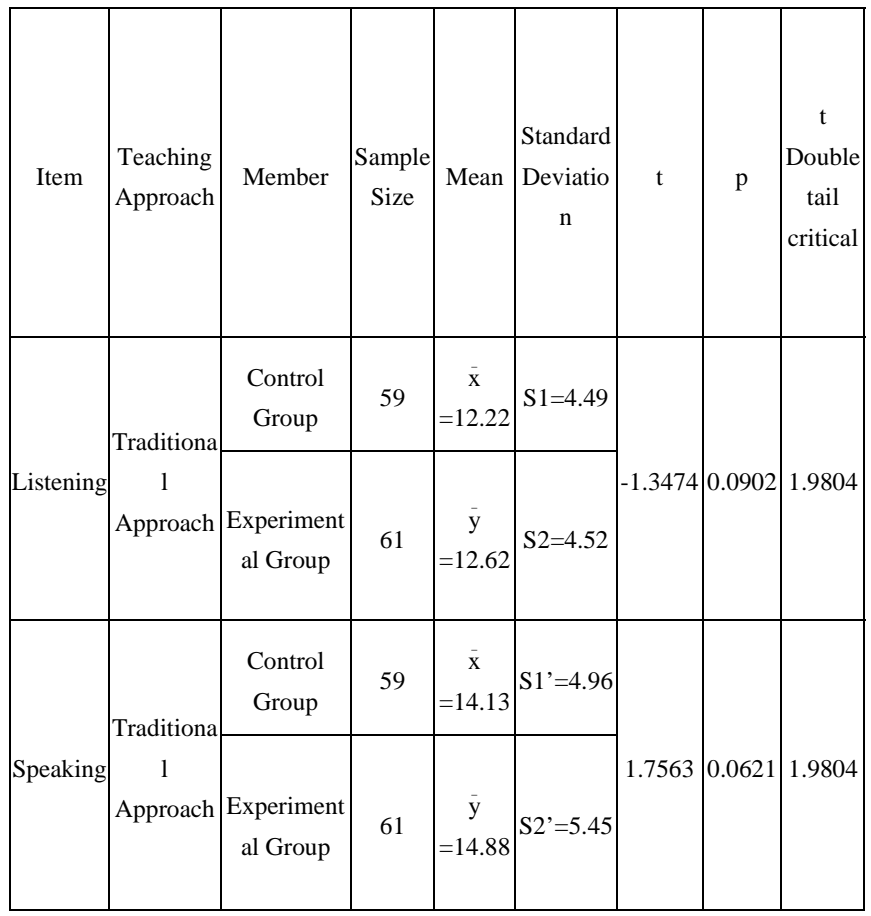

2) Implementation of teaching

Experimental group (multimodal video discourse strategy teaching group)

According to Willis' three phases for task-based teaching model:

a) Pre-task phase, including introduction topics and preparation for the task which outstands teacher's "dominant" function; Teachers provide students with useful input, activate the relevant knowledge and appreciation of movie language skills to help students in a networked environment understand the task of theme, content and goals, mobilize the students interest and enthusiasm, guide students to the preparation of task. To fulfill the task, first we should establish cooperative group. According to Deng Yingling's "homogeneity between groups, heterogeneity in group", teachers guide students to establish cooperative team which are divided by listening and speaking test and class performance, circle of friends according to students' gender and their own willingness and ability of organization and communication, about 4 to 5 students in each group. The group forms diamond structure according to language and comprehensive ability, strong and weak type around 20\% students, including one recommended by group to become a leader who plays the role of organization, motivation and contact. This phase includes: rendering tasks; assignment; skill training.

b) Task-cycle (the implementation phase of the task), including the participant's activities, plans and reports. Making students' prominent- "principal part” at this stage, the students design and perform the task in which way they like. Teachers select appropriate videotext and activate students' ability of film and television appreciation knowledge, language skills and cultural background by words and phrases. Students in the task driven watch video online before class and prepare the teacher's questions from video content. Task type for cooperative learning according to the difficult index can be divided into mandatory task, speculative task, competitive task, communicative task, investigative task and task of debate and design. Each task score percentages designed according to the different weight ratio. Cooperative learning is based on the two aspects: positive interdependence and individual accountability, which pay attention to the rational division in activity and effective organization. This phase includes: collection of videos, role assignments, film imitation, plot discussion etc.

c) Post-task (evaluation phase), constructs "teacherstudent" "students-students" interactive mode, to encourage them to participate in the discussion and analysis actively. Students assess each other from the film language feature, application, communication effectiveness, coordination and other aspects of individual and group activities through comment, learn from each other and improve together. Teacher's comments combine with the characteristics of western culture, language skills and the integrated ability of language use. Teachers may use the combination approaches, "quantitative evaluation" and "qualitative description”, to assess students from language skills, culture, and other aspects. Each student makes self \& mutual evaluation to himself and team member in language skills, participation, progress, cooperation spirit, comprehensive ability, and evaluates the overall performance of the group. Teachers investigate each group member from the language ability, participation, creation, cooperation and learning effect, etc. Self-evaluation, mutual evaluation in students and teacher's evaluation account for $25 \%, 25 \%$ and $50 \%$ respectively. The evaluation mechanism forms $3 \mathrm{~d}$ structure including process evaluation and result evaluation, which is full of stability and fairness in the English audio-visual teaching evaluation.

The control group (traditional audio-visual teaching method group)

a) Students preview the text before class, recite the corresponding new words

b) The textbook is "new horizon college English audiovisual course", according to traditional methods to train students in class based on close to real communicative situations of single mode or dual modal mechanical listening exercises, teachers analyze textbook, students answer the problems related text.

3) Post-test

After two semesters teaching, we test two groups of language ability from depth and width, we employ the data in a unified final exam in the university, take listening and speaking each with $20 \%$ as the full mark to measure output of students' foreign language level. 
Table 2Post-test Data Analysis of Two Groups in the

\begin{tabular}{|c|c|c|c|c|c|c|c|c|}
\hline \multicolumn{9}{|c|}{ Second Term Fig 2} \\
\hline Item & $\begin{array}{l}\text { Teaching } \\
\text { Approach }\end{array}$ & Member & $\left|\begin{array}{c}\text { SampleSi } \\
\text { ze }\end{array}\right|$ & Mean & $\begin{array}{l}\text { Standard } \\
\text { Deviation }\end{array}$ & $\mathrm{t}$ & $\mathrm{p}$ & $\begin{array}{c}\text { t Double } \\
\text { tail } \\
\text { critical }\end{array}$ \\
\hline \multirow{2}{*}{ Listening } & $\begin{array}{c}\text { Tradition } \\
\text { al } \\
\text { Approach }\end{array}$ & $\begin{array}{l}\text { Control } \\
\text { Group }\end{array}$ & 59 & $\overline{\mathrm{x}}=12.78$ & $S 1=4.26$ & \multirow{2}{*}{ 2. 7321} & \multirow{2}{*}{0.0005} & \multirow{2}{*}{ 1. 9812} \\
\hline & $\begin{array}{c}\text { Using } \\
\text { Videos }\end{array}$ & $\begin{array}{l}\text { Experiment } \\
\text { al Group }\end{array}$ & 61 & $\bar{y}=15.92$ & S2 $=2.96$ & & & \\
\hline \multirow{2}{*}{ Speaking } & $\begin{array}{c}\text { Tradition } \\
\text { al } \\
\text { Approach }\end{array}$ & $\begin{array}{l}\text { Control } \\
\text { Group }\end{array}$ & 59 & $\bar{x}=14.56$ & $S 1^{\prime}=5.19$ & \multirow{2}{*}{ 3. 4582} & \multirow{2}{*}{0.0000} & \multirow{2}{*}{ 1. 9812} \\
\hline & $\begin{array}{c}\text { Using } \\
\text { Videos }\end{array}$ & $\begin{array}{l}\text { Experiment } \\
\text { al Group }\end{array}$ & 61 & $\bar{y}=17.32$ & S2' $=3.54$ & & & \\
\hline
\end{tabular}

\section{RESULT ANALYSIS AND DISCUSSION}

Let's read table 1: Under the condition of $95 \%$ confidence level for double check the difference between the sample mean, establish a hypothesis H0 : experimental group and control group students have no significant difference in listening and speaking, namely the M1-M2 = 0 , $|\mathrm{t}|<1.9804$, the fall in the acceptable region, therefore assuming $\mathrm{H} 0$, namely at the beginning of the experiment, the level of experimental group and control group in listening and speaking is no significant differences. Let's read table 2: $|t|>1.9812$, the fall in the rejection region, thus assuming $\mathrm{H} 0$, namely after the experiment, the experimental group and control group there are significant differences on students in listening and speaking.

In order to fully understand the students' cognition of task-oriented cooperative learning and its influence on English audio-visual-oral teaching, the researchers design questionnaire according to Likert five scale way, integrate most of the students' idea that the videotext by task-oriented cooperative learning strategy can improve the learning interest and motivation (75.8\%), language skills (61.3\%), and the ability to learn (69.7\%), strengthening students' selfconfidence $(75.4 \%)$, cultivating a strong will (78.5\%) and self emotion regulation (55.7\%), the biggest advantage is embodied in the social communication ability (87.9\%), the cultivation of the spirit of cooperation (93.7\%). The cooperative mode reduces the anxiety of the students in the process of learning, enhances the students' self-confidence, eliminates the learners' psychological barriers effectively and achieves the purpose of improving the ability of audiovisual-oral.

The second question for the research is students' recognition of different types of task. The recognition result of the mandatory task and speculative task is about $14.3 \%$, competitive tasks19.7\%, communicative tasks and investigative task about $22.3 \%$, debate tasks $27 \%$ and design task $16.7 \%$. The research shows students do not escape competition in task-based cooperative learning. They like challenging when facing higher request for innovation ability and comprehensive quality. Students have higher recognition in the evaluation mechanism of cooperative learning, at 92.5\%. In the self and mutual assessment, these students who were born in the post 90 century have distinct personality, most students have higher self recognition and activity participation, can actively cooperate with the team member, satisfy with their performance. Studies show that evaluation mechanism avoids the traditional disadvantages of only teachers' evaluation, eases the students' test anxiety and nervousness, conforms to the regulation of language teaching, and also enriches the evaluation system.

In response to the third question of task based cooperative learning strategy, which is more effective between the group of "advantage", or "vulnerable group"? We found that the vulnerable group students can get more help in cooperation and improvement. Audio-visual-oral course is to attach importance to "vulnerable group" from cooperative groups at the beginning. It respects the students' self choice and learning rules, reasonable grouping to achieve the best partner. In the practical task, every team member has an equal opportunity to be assigned the task. Mutual evaluation mechanism is also very good solution to the traditional system of ultimate evaluation which is onesided surface impression that may occur.

\section{CONCLUSION}

This research is on the theoretical basis of Kress G \& van Leeuwen's “Reading Images: The Grammar of Visual Design," Baldry and Thibault's "Multimodal Transcription and Text Analysis". By means of multimodal videotext learning strategy which is the task-oriented cooperative learning, it is obviously with the teaching mode that not only the students' audio-visual-oral ability has great improvement, but also their autonomous learning ability, subject consciousness, language comprehensive ability and cultural quality have played a considerable role. It plays a positive role in guiding the practice in the new reform of English teaching. It fully demonstrates that the topic is credible in theory, and it is also possible in practice.

\section{BIBLIOGRAPHY}

[1] Eve, B. "Multimodality. Literacy and Texts: Developing Discourse" [J]. Journal of Early Childhood Literacy, 2009(9), pp.156

[2] Kress, G.\& van Leeuwen, T. "Reading Images: The Grammar of Visual Design” [M]. Burwood:Brown Prior Anderson,1996 pp133

[3] Cope, B. \& Kalantzis, M. "Multiliteriacies: Literacy leaning and the design of social futures"[M]. New York: Routledge 2000, pp3-8

[4] Baldry, A. P. \& P. J. Thibault. "Multimodal Transcription and Text Analysis” [M]. London: Equinox, 2006.pp15-36

[5] Hu Zhuanglin. "Multimodal Social Semiotics Research" [J]. Language Teaching and Research, 2007 (1) ,pp1-10

[6] Ellis R. "Task-based language learning and teaching" [M].Oxford: Oxford University Press, 2003 pp132

[7] Willis, J. A "Framework for Task-based Learning" [M]. London: Longman, 1996. Pp78 